\title{
Development and validation of the disease-specific QOL-CD quality of life questionnaire for patients with Cushing's disease
}

\author{
Michael D. Cusimano, MD, PhD, ${ }^{1,2}$ Tony Q. Huang, ${ }^{1}$ Anthony Marchie, MD, ${ }^{1}$ Harley S. Smyth, MD, ${ }^{1}$ \\ and Kalman Kovacs, MD³
}

'Division of Neurosurgery, Department of Surgery, and 'Division of Pathology, Department of Laboratory Medicine, St. Michael's Hospital, University of Toronto; and 2Dalla Lana School of Public Health, University of Toronto, Ontario, Canada

\begin{abstract}
OBJECTIVE Cushing's disease (CD) patients experience a range of debilitating symptoms that impair quality of life $(\mathrm{QOL})$ as assessed using generic measures. These generic measures are inadequate to capture the disease-specific burden of illness. The development of the CD-specific QOL-CD measure of QOL using items generated by CD patients and healthcare professionals will provide a holistic assessment of patient outcomes and efficacy of novel therapies.

METHODS A total of 96 CD patients participated. A list of 177 items (version 1.0) was generated by treated CD patients $(n=9)$, caregivers $(n=2)$, healthcare providers $(n=7)$, and results of a MEDLINE search. Item reduction was performed through content analysis and dual scaling. Patients' rating of importance was incorporated to reduce to a final version of 56 items (version 3.0). Evidence for test-retest reliability was sought through administering the QOL-CD 1 week apart and Cronbach's $\alpha$ of each subscale. Construct validity was assessed through extreme group analysis and comparison with the normal Canadian population. Concurrent validity was sought through comparison with the SF-36, Functional Assessment of Cancer Therapy-Brain (FACT-Br), and Karnofsky Performance Status (KPS). Perioperative testing was conducted on CD patients $(n=25)$ against nonfunctioning pituitary adenoma controls $(n=25)$ through pre- and postoperative testing.
\end{abstract}

RESULTS A total of 96 CD patients (86 females and 10 males; mean age $45.23 \pm 14.16$ years) participated. The QOLCD was feasible (mean completion time 15 minutes, with $70 \%$ believing accurate capture of QOL), reliable (CD 1 week apart: $r=0.86$; control 1 week apart: $r=0.83$; Cronbach's $\alpha$ : general health $=0.73$, emotional health $=0.85$, physical health $=0.78$, mental status $=0.82$, social well-being $=0.63$, medical treatment $=0.54$ ), and valid (extreme group testing $p<0.001$; SF-36 and QOL-CD general health: $r=0.56$, social well-being: $r=0.21$, emotional health: $r=0.61$, total score: $r=0.58$; FACT-Br and QOL-CD physical health: $r=0.47$, social well-being: $r=0.21$, emotional health: $r=0.34$, total score: $r=0.68$; KPS and QOL-CD general health: $r=0.32$, total score: $r=0.14$ ). Perioperative testing of CD patients $(n=25)$ demonstrated improvement in all subscales postoperatively, with a significant difference in emotional health $(p<$ $0.001)$ and physical health $(p<0.001)$.

CONCLUSIONS The QOL-CD questionnaire has been developed for patients with CD and has demonstrated evidence for validity and reliability.

https://thejns.org/doi/abs/10.3171/2020.3.FOCUS2044

KEYWORDS Cushing's disease; Cushing's syndrome; hypercortisolism; pituitary adenoma; quality of life; QOL-CD

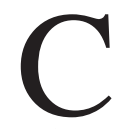

USHING's disease (CD), an endogenous form of Cushing's syndrome (CS), is associated with a range of debilitating symptoms that cause significant physical, emotional, social, and functional impairments as a result of hypercortisolism. ${ }^{18,19,23,25,29,34,39,40}$ A number of studies have reported that the quality of life (QOL) in CD patients is significantly impaired relative to that in patients with other pituitary adenomas and the general population using generic measures. ${ }^{7,14,43}$ Patients with active CD often report experiencing sudden mood swings, violent outbursts, and crying spells, in addition to visible physical changes. ${ }^{5}$ The impact and multidimensionality of $\mathrm{CD}$ symptomatology

ABBREVIATIONS CD = Cushing's disease; $C S=$ Cushing's syndrome; FACT-Br = Functional Assessment of Cancer Therapy-Brain; HCP = healthcare provider; KPS = Karnofsky Performance Status; NFPA = nonfunctioning pituitary adenoma; $\mathrm{QOL}=$ quality of life; $\mathrm{TSS}=$ transsphenoidal surgery.

SUBMITTED January 25, 2020. ACCEPTED March 3, 2020.

INCLUDE WHEN CITING DOI: 10.3171/2020.3.FOCUS2044. 
emphasizes the need for a holistic, disease-specific QOL measure.

In previous literature, $\mathrm{QOL}$ in $\mathrm{CD}$ has been primarily described using generic measures alone or in conjunction with other domain-specific measures. Although generic QOL measures have the advantage of being applicable to any population, they may not fully capture the nuances associated with $\mathrm{CD}$. Therefore, the purpose of this study was to develop and validate a comprehensive, diseasespecific QOL questionnaire for CD that could be used in clinical settings for assessment of disease progression and outcomes and efficacy of novel therapies.

\section{Methods}

\section{Identification of a Patient and Control Population}

Participants were selected from a list of patients diagnosed with $C D$ presenting to the Neurosurgery Clinic at St. Michael's Hospital in Toronto, Ontario, Canada. A total of 168 participants were recruited for this study after obtaining informed consent. The participants consisted of treated CD patients $(n=96)$, treated nonfunctioning pituitary adenoma (NFPA) patients $(n=25)$, healthy individuals $(n=38)$, medical specialists $(n=7)$, and caregivers $(n=2)$. The CD patients were involved in both the development phase $(n=31)$ and validation phase $(n=65)$. The CD patients involved in the validation phase were further divided into a treated group (validation group 1, $\mathrm{n}=40$ ) and a prospective group (validation group $2, \mathrm{n}=$ 25), which was followed perioperatively. The healthy individuals (validation control group 1) and prospective NFPA patients (validation control group 2) served as controls for the validation phase. The CD patients were included in the study if they had biochemically and radiologically confirmed CD and were successfully treated with transsphenoidal surgery (TSS), as defined by biochemical remission with a postoperative nadir of morning cortisol less than $100 \mathrm{ng} / \mathrm{ml}$ and the need for immediate post-TSS glucocorticoid replacement. This selection was motivated by previous investigations of QOL, in which QOL was reported to improve post-TSS within CD patients considered to be in remission. ${ }^{14,28,43}$ This provides a well-defined cohort, from which the QOL-CD's sensitivity to change could be clearly assessed. All patients were asked to disclose on a demographics questionnaire any prior surgeries, current and previous medications, and additional forms of treatments. The results from the demographics questionnaire, as indicated by the participants involved in the validation phase, are summarized in Table 1.

\section{Development Phase}

\section{Item Selection}

A group of 9 female CD patients successfully treated with TSS, 2 caregivers, 3 nurses, and 4 medical specialists were invited to a series of 3 focus group meetings, in which QOL issues relevant to CD were generated and discussed. The age, education, socioeconomic status, and years of schooling of this group were not significantly different from those of the other CD patients within the study. A MEDLINE search of literature was conducted, and issues pertaining to QOL in $\mathrm{CD}$ were identified. The QOL issues identified by the patients, caregivers, healthcare providers (HCPs), and MEDLINE search generated 177 items (version 1.0). No new items were generated following this stage.

\section{Item Reduction}

Version 1.0 was presented to the $9 \mathrm{CD}$ patients and 7 HCPs for feedback. The CD patients were instructed to rate the items based on their impact and relevance to QOL. Version 1.0 was then reduced using content analysis, which aided in the elimination of redundancies identified by both patients and HCPs. The reduced list (version 2.0) consisted of 105 items; 90 of these items were selected by patients alone based on ranked importance, and 15 items were selected by both patients and HCPs. From the $9 \mathrm{CD}$ patients invited for review, 5 patients responded and arrived at a consensus that the list accurately captured the essential elements of how CD has affected them or others with the condition.

The $\mathrm{CD}$ patients arrived at a consensus to categorize the items into 5 distinct subscales pertaining to CD: general health, emotional health, physical health, social well-being, and medical treatment. A sixth mental status domain was later added by the investigators. The general health subscale represented energy levels, general well-being, and activities of daily living. The emotional health subscale was based on symptoms of depression, including sadness, helplessness, and mood swings. The physical health subscale encompassed a range of physical signs and symptoms characteristic of $\mathrm{CD}$, including, but not limited to, hirsutism, changes in body weight, moon facies, and hypertension. The mental status subscale focused on cognitive function, such as memory, concentration, and judgment. The social well-being subscale pertains to normal social function, such as support from and relationship with family and friends. The medical treatment subscale contained content relevant to treatment outcome and satisfaction with the HCP. Respondents were asked to rate items on a 3-point Likert-type scale, in which 1 represents a good QOL and 3 indicates a poor QOL. Version 2.0 was subsequently distributed to 20 individuals, which included physicians, nurses, physiotherapists, and laypersons, for feedback on wording, grammar, and format, resulting in version 2.1.

Version 2.1 was mailed to a different group of $25 \mathrm{CD}$ patients for further review and ranking; 22 questionnaires were completed and returned. The patients were instructed to retrospectively recall their experience prior to surgical intervention when ranking the items for importance. The questionnaire responses were analyzed using dual scaling and factor analysis to assess the general structure of the questionnaire and to identify items that discriminated the scores among patients. ${ }^{20}$ Dual scaling was also used to identify 20 items with the most reliable scores, of which 12 were the same as those identified by patients' rank scores. Through this, the 105 items were further reduced to the 56 items of the final QOL-CD questionnaire (version 3.0). Version 3.0 of the QOL-CD questionnaire is included as Supplement 1.

\section{Validation Phase}

Reliability Testing

A package containing 2 sets of version 3.0, along with 
TABLE 1. Demographics of the CD and control participants involved within the study, as reported by the participants using a demographics questionnaire

\begin{tabular}{|c|c|c|c|c|c|c|}
\hline & $\begin{array}{l}\text { Treated CD } \\
\quad(\text { VG 1) }\end{array}$ & $\begin{array}{l}\text { Healthy Control } \\
\text { (VCG 1) }\end{array}$ & \multicolumn{2}{|c|}{$\begin{array}{l}\text { Prospective CD } \\
\quad \text { (VG 2) }\end{array}$} & \multicolumn{2}{|c|}{$\begin{array}{l}\text { Prospective NFPA } \\
\text { (VCG 2) }\end{array}$} \\
\hline No. of patients & 40 & 38 & \multicolumn{2}{|c|}{25} & \multicolumn{2}{|c|}{25} \\
\hline \multicolumn{7}{|l|}{ Sex } \\
\hline Female & $36(90.0)$ & $35(92.1)$ & \multicolumn{2}{|c|}{$21(84.0)$} & \multicolumn{2}{|c|}{$5(20.0)$} \\
\hline Male & $4(10.0)$ & $3(7.9)$ & \multicolumn{2}{|c|}{$4(16.0)$} & \multicolumn{2}{|c|}{$20(80.0)$} \\
\hline Treatment Status & Post-TSS & NA & Pre-TSS & Post-TSS & Pre-TSS & Post-TSS \\
\hline \multicolumn{7}{|l|}{ Age, yrs } \\
\hline Mean & 46.44 & 42 & 42.48 & 43.44 & 58.04 & 58.52 \\
\hline Range & $20-70$ & $24-60$ & $15-76$ & $16-77$ & $22-81$ & $22-81$ \\
\hline \multicolumn{7}{|l|}{ Periop duration from TSS, mos } \\
\hline Mean & 71.24 & NA & 3.78 & 6.71 & 3.45 & 3.55 \\
\hline SD & 52.31 & NA & 4.31 & 13.39 & 2.60 & 3.24 \\
\hline \multicolumn{7}{|l|}{ Additional treatment } \\
\hline None & 15 & NA & 15 & 11 & 18 & 16 \\
\hline Undisclosed & 5 & NA & 4 & 4 & 6 & 8 \\
\hline Only 1 type of additional treatment & 17 & NA & 5 & 7 & 1 & 1 \\
\hline Radiation or GKRS & 2 & & 0 & 0 & 0 & 0 \\
\hline Ketoconazole (Nizoral) & 2 & & 3 & 3 & 0 & 0 \\
\hline $\begin{array}{l}\text { Bromocriptine (Parlodel), cabergoline (Dostinex), \& quinagolide (Nor- } \\
\text { prolac) }\end{array}$ & 1 & & 1 & 1 & 0 & 0 \\
\hline Octreotide (Sandostatin) & 0 & & 1 & 0 & 0 & 0 \\
\hline Metyrapone (Metopirone) & 0 & & 0 & 0 & 0 & 0 \\
\hline Hormone therapy & 10 & & 0 & 3 & 1 & 0 \\
\hline Other & 2 & & 0 & 0 & 0 & 1 \\
\hline$>1$ type of additional treatment & 3 & NA & 1 & 3 & 0 & 0 \\
\hline $\begin{array}{l}\text { Ketoconazole (Nizoral) \& bromocriptine (Parlodel), cabergoline } \\
\text { (Dostinex), \& quinagolide (Norprolac) }\end{array}$ & 0 & & 1 & 2 & 0 & 0 \\
\hline Ketoconazole (Nizoral) \& octreotide (Sandostatin) & 0 & & 0 & 1 & 0 & 0 \\
\hline Ketoconazole (Nizoral) \& hormone therapy & 2 & & 0 & 0 & 0 & 0 \\
\hline Radiation or GKRS, ketoconazole (Nizoral), \& hormone therapy & 1 & & 0 & 0 & 0 & 0 \\
\hline
\end{tabular}

GKRS = Gamma Knife radiosurgery; NA = not applicable; VCG = validation control group; VG = validation group .

Values represent the number of patients (\%) unless stated otherwise.

a copy of the SF-36, Functional Assessment of Cancer Therapy-Brain (FACT-Br), and Karnofsky Performance Status (KPS), was mailed to 77 additional TSS-treated $\mathrm{CD}$ patients in biochemically confirmed remission, in which 40 sets were completed and returned (validation group 1). A group of 38 healthy individuals without CD also completed 2 sets of the QOL-CD (validation control group 1). Validation group 1 and validation control group 1 were instructed to complete the questionnaires and to return the first set immediately $\left(\mathrm{T}_{0}\right)$ followed by the second 1 week after $\left(T_{1}\right)$ under the same environment. Reliability for the QOL-CD was assessed through the correlation between the questionnaires completed at $\mathrm{T}_{0}$ and $\mathrm{T}_{1}$. Pearson's correlation coefficient and Student t-test were calculated for the set. The internal consistency of each unidimensional subscale was also assessed by calculating Cronbach's $\alpha .^{4}$

\section{Validation Testing}

Evidence of content validation arose from a number of sources. First, the patient-centered process undertaken to generate and rank relevant items for the questionnaire was thorough and followed a deliberate protocol to generate items relevant to patients. Additional evidence for construct validity was assessed by comparing the mean scores for the 2 extreme groups among the CD patients, which consisted of patients with extreme scores on the SF-36. The differences between the extreme groups were evaluated using a Student t-test of QOL-CD scores. Construct validity was further evaluated through comparing the SF36 subscale scores of $\mathrm{CD}$ patients with the normative $\mathrm{Ca}$ nadian population reported by Hopman et al. ${ }^{8}$

Furthermore, evidence for criterion validity was sought by calculating the Pearson's correlation coefficient of the total and subscale scores between the QOL-CD and the 


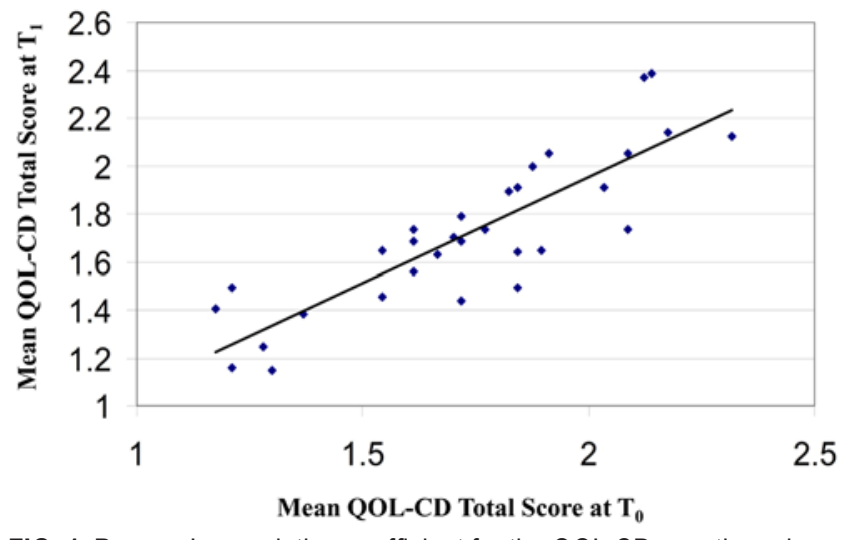

FIG. 1. Pearson's correlation coefficient for the QOL-CD questionnaire completed at $T_{0}$ and $T_{1}$ (1 week apart) by patients who completed both sets in validation group $1(n=31) r=0.86, p=0.42$.

highly validated measures using validation group $1 .^{17,24,31}$ The total and subscale scores of the generic 8-domain SF36 were used to provide concurrent validity for the QOLCD total score, general health, social well-being, and emotional health subscales. ${ }^{37}$ The total and subscale scores of the FACT-Br were used to provide further evidence for concurrent validity for the QOL-CD total score, physical health, social well-being, and emotional health subscales. ${ }^{3,41}$ The KPS is a unidimensional measure of physical and functional status of cancer patients and provided a contrast with the multidimensional QOL-CD. ${ }^{10,11}$

Additionally, construct validity was sought by assessing QOL-CD scores using validation group 2 and validation control group 2, who completed the questionnaire prospectively, before and after TSS. The QOL-CD was administered in a clinical setting at 2 time points: prior to TSS and following successful TSS. In this process, we tested the hypothesis of whether the QOL-CD questionnaire could capture change in QOL perioperatively. The changes in QOL within the groups and a time point comparison between groups were analyzed using a Wilcoxon signed-rank test. Cronbach's $\alpha$ was calculated at each time point for both groups.

\section{Results}

\section{Feasibility of Testing}

The questionnaire return rate for completing the first mailed set was $51.9 \%(n=40)$ and that for the second set was $77.5 \%(n=31)$. The mean time for completion of the QOL-CD was 15 minutes, and there were no reported difficulties with completion. When asked whether the questionnaire accurately captured their QOL when they had CD, $70.0 \%(n=28)$ of patients answered "yes."

\section{Test-Retest Reliability}

The mean total scores on the 2 QOL-CD questionnaires administered to validation group 1 at $\mathrm{T}_{0}$ and 1 week later at $T_{1}(n=31)$ were not significantly different $\left(\mathrm{T}_{0}\right.$ mean total score $1.73 ; \mathrm{T}_{1}$ mean total score $1.72 ; \mathrm{p}=$ 0.42 ). The Pearson correlation coefficient of the 2 sets was 0.86 (Fig. 1). Similarly, the mean test-retest scores of the control subjects $(n=38)$ were identical at both $T_{0}$ and $T_{1}$
TABLE 2. Mean QOL-CD scores reported by validation group 1

\begin{tabular}{llc}
\hline QOL-CD Subscale & VG $1(\mathrm{n}=40)$ & Cronbach's $\alpha$ \\
\hline General health & $1.71 \pm 0.30$ & 0.73 \\
\hline Emotional health & $1.87 \pm 0.22^{*}$ & 0.85 \\
\hline Physical health & $1.74 \pm 0.31^{*}$ & 0.78 \\
\hline Mental status & $1.82 \pm 0.18^{*}$ & 0.82 \\
\hline Social well-being & $1.39 \pm 0.18$ & 0.63 \\
\hline Medical treatment & $1.34 \pm 0.27$ & 0.54 \\
\hline
\end{tabular}

Items are rated on a 3-point scale, in which 1 is the best possible QOL and 3 is the worst possible QOL. Values represent mean \pm SD unless stated otherwise. Cronbach's $\alpha$ of validation group 1 was calculated for each subscale.

* Statistically significant $(p<0.05)$.

$\left(\mathrm{T}_{0}\right.$ total score $1.40 ; \mathrm{T}_{1}$ total score $\left.1.40 ; \mathrm{p}=0.90\right)$. The Pearson correlation coefficient between $\mathrm{T}_{0}$ and $\mathrm{T}_{1}$ scores was 0.83. A strong correlation between $T_{0}$ and $T_{1}$ was found for both groups. The scores of the validation group 1 (1.73) and validation control group 1 (1.37) were significantly different $(\mathrm{p}=0.0012)$. The Cronbach's $\alpha$ values of each QOL-CD subscale for validation group 1 are listed in Table 2. A value of 0.7 is indicated to be acceptable; however, lower thresholds are also used in the literature. ${ }^{21}$ Cronbach's $\alpha$ demonstrates that the internal consistency of each subscale was adequate.

\section{Concurrent Validity}

Table 3 shows that, except for social well-being, the total and subscale scores on the QOL-CD correlated moderately well with the SF-36 and the FACT-Br. The KPS scores, however, did not correlate well with the QOL-CD.

\section{SF-36 Comparisons With Canadian Normative Data}

Figure 2 shows that SF-36 scores from the 36 females in validation group 1 were lower than those of 6526 females in the normative Canadian population. The physical, emotional, and social domains were most affected by the disease relative to the normal population. Since there were only 4 male CD patients in validation group 1, the statistical power was insufficient for a comparison with the normative data.

\section{Extreme Group Testing}

Extreme groups were defined by their scores on the SF36 . The highest-scoring extreme group $(n=10$; combined mean SF-36 score 163.1) and lowest-scoring extreme group ( $n=10$; combined mean SF-36 score 80.4) were found to be significantly different $(\mathrm{p}<0.001)$. CD patients with the highest mean combined SF-36 score (higher score indicating better QOL) had significantly lower scores on the QOL-CD (lower score indicating better QOL) than the group with the lowest SF-36 scores.

\section{Subscale Scores}

The mean subscale scores obtained from validation group 1 are summarized in Table 2 . The emotional health ( $\mathrm{p}<0.001)$, physical health $(\mathrm{p}=0.008)$, and mental status $(\mathrm{p}=0.002)$ subscales were most impaired by CD. 
TABLE 3. Pearson's correlation coefficient measured between the QOL-CD subscales and other validated QOL measures using scores from validation group 1

\begin{tabular}{clc}
\hline \multicolumn{1}{c}{ Other QOL Measures } & \multicolumn{1}{c}{ QOL-CD } & $r$ \\
\hline SF-36 & & \\
\hline General health & General health & 0.56 \\
\hline Social function & Social well-being & 0.21 \\
\hline Emotional & Emotional health & 0.61 \\
\hline Total score & Total score & 0.58 \\
\hline FACT-Br & & \\
\hline Physical health & Physical health & 0.47 \\
\hline Social/family well-being & Social well-being & 0.21 \\
\hline Emotional well-being & Emotional health & 0.34 \\
\hline Total score & Total score & 0.68 \\
\hline KPS & & \\
\hline Total score & General health & 0.32 \\
\hline Total score & Total score & 0.14 \\
\hline
\end{tabular}

\section{Prospective Preoperative and Postoperative Cohort Testing}

Table 4 summarizes the mean QOL-CD questionnaire scores from each subscale obtained from validation group 2 and validation control group 2 that were completed preand postoperatively. In validation group 2, a significant difference in score between the pre-TSS and post-TSS time points was observed in the emotional health $(\mathrm{p}=$ $0.003)$ and physical health $(\mathrm{p}<0.001)$ subscales, whereas in validation control group 2, only the medical treatment subscale $(\mathrm{p}=0.003)$ was significantly different. Between validation group 2 and validation control group 2, a significant difference in scores was observed at the pre-TSS time point across all subscales except for medical treatment, whereas all subscales were significantly different post-TSS. Cronbach's $\alpha$ values of validation group 2 for each subscale pre-TSS and post-TSS are listed in Table 4.

\section{Discussion}

A patient-centered, disease-specific questionnaire for CD patients was developed and shown to have good evidence for validity and reliability during testing. The QOL$\mathrm{CD}$ questionnaire scores were also highly reproducible, as indicated by the test-retest reliability coefficient. The QOL-CD questionnaire developed appears to be acceptable to patients, and its use in a clinical setting appears feasible. In addition, control group comparisons demonstrated a statistically significant difference between $C D$ patients and healthy subjects, indicating that the QOL-CD questionnaire can discriminate between patients with the disease and those without.

The significant difference between the scores of the extreme groups also supports construct validity by demonstrating that the instrument is sensitive to QOL differences among CD patients who report contrasting perceptions. In addition, the SF-36 scores of the CD patients were markedly lower than those of the normal Canadian population, which indicates that $\mathrm{CD}$ patients experienced an impaired QOL relative to the normal population, as measured by a generic instrument. Since the generic SF-36 and the QOL$\mathrm{CD}$ questionnaire were well correlated, it is likely that the QOL-CD questionnaire was indeed measuring impairment in QOL among CD patients. The SF-36 comparison with the normal Canadian population also reveals that the

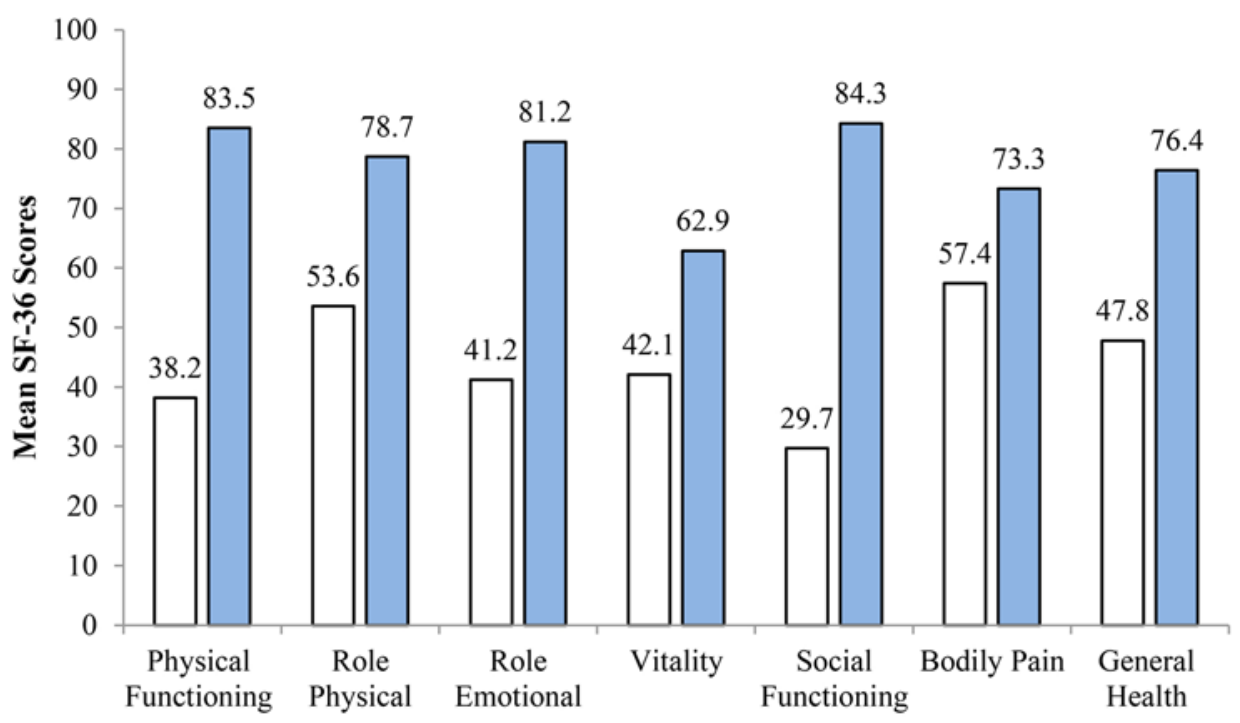

QOL-CD Subscale

口CD Group $\quad$ Normal Canadian Population

FIG. 2. Mean SF-36 scores of female patients with $C D$ in validation group 1 ( $n=36$ females) compared with the normal Canadian population ( $n=6526$ females) reported by Hopman et al. ${ }^{8}$ 
TABLE 4. Mean QOL-CD scores reported by the prospective patients

\begin{tabular}{|c|c|c|c|c|c|c|c|c|c|c|c|c|}
\hline \multirow[b]{2}{*}{$\begin{array}{l}\text { QOL-CD } \\
\text { Subscale }\end{array}$} & \multicolumn{5}{|c|}{ VG $2(n=25)$} & \multicolumn{5}{|c|}{ VCG $2(n=25)$} & \multicolumn{2}{|c|}{$\begin{array}{l}\text { VG2/VCG2 } \\
\text { Comparison }\end{array}$} \\
\hline & $\begin{array}{c}\text { Mean } \\
\text { Pre-TSS } \\
\text { Score }\end{array}$ & $\begin{array}{c}\alpha \\
\text { Pre-TSS }\end{array}$ & $\begin{array}{c}\text { Mean } \\
\text { Post-TSS } \\
\text { Score }\end{array}$ & $\begin{array}{c}\alpha \\
\text { Post-TSS }\end{array}$ & $\begin{array}{c}p \\
\text { Value }\end{array}$ & $\begin{array}{c}\text { Mean } \\
\text { Pre-TSS } \\
\text { Score }\end{array}$ & $\begin{array}{c}\alpha \\
\text { Pre-TSS }\end{array}$ & $\begin{array}{c}\text { Mean } \\
\text { Post-TSS } \\
\text { Score }\end{array}$ & $\begin{array}{c}\alpha \\
\text { Post-TSS }\end{array}$ & $\begin{array}{c}p \\
\text { Value }\end{array}$ & $\begin{array}{c}\text { Pre-TSS } \\
\text { p Value }\end{array}$ & $\begin{array}{c}\text { Post-TSS } \\
\text { p Value }\end{array}$ \\
\hline $\begin{array}{l}\text { General } \\
\text { health }\end{array}$ & $2.24 \pm 0.40$ & 0.82 & $2.22 \pm 0.36$ & 0.80 & 0.363 & $1.76 \pm 0.47$ & 0.83 & $1.57 \pm 0.46$ & 0.86 & 0.126 & $<0.001^{*}$ & $<0.001^{*}$ \\
\hline $\begin{array}{l}\text { Emotional } \\
\text { health }\end{array}$ & $2.25 \pm 0.32$ & 0.80 & $1.93 \pm 0.51$ & 0.90 & $0.003^{*}$ & $1.47 \pm 0.41$ & 0.89 & $1.36 \pm 0.40$ & 0.91 & 0.296 & $<0.001^{*}$ & $<0.001^{*}$ \\
\hline $\begin{array}{l}\text { Physical } \\
\text { health }\end{array}$ & $2.17 \pm 0.19$ & 0.69 & $1.74 \pm 0.33$ & 0.81 & $<0.001^{*}$ & $1.47 \pm 0.29$ & 0.69 & $1.33 \pm 0.19$ & 0.79 & 0.059 & $<0.001^{*}$ & $<0.001^{*}$ \\
\hline $\begin{array}{l}\text { Mental } \\
\text { status }\end{array}$ & $2.01 \pm 0.52$ & 0.83 & $1.83 \pm 0.57$ & 0.89 & 0.251 & $1.52 \pm 0.46$ & 0.83 & $1.38 \pm 0.43$ & 0.89 & 0.130 & $0.002^{*}$ & $0.009^{*}$ \\
\hline $\begin{array}{l}\text { Social } \\
\text { well-being }\end{array}$ & $1.62 \pm 0.37$ & 0.82 & $1.55 \pm 0.39$ & 0.71 & 0.697 & $1.38 \pm 0.41$ & 0.82 & $1.24 \pm 0.36$ & 0.71 & 0.065 & $0.028^{*}$ & $0.004^{*}$ \\
\hline $\begin{array}{l}\text { Medical } \\
\text { treatment } \dagger\end{array}$ & $1.58 \pm 0.20$ & & $1.52 \pm 0.35$ & & 0.551 & $1.42 \pm 0.35$ & & $1.16 \pm 0.25$ & & $0.003^{*}$ & 0.122 & $<0.001^{*}$ \\
\hline
\end{tabular}

Cronbach's $\alpha$ for the prospective patients was calculated for each subscale pre-TSS and post-TSS.

* Statistically significant $(p<0.05)$.

† The $\alpha$ value for the medical treatment subscale could not be computed due to response inadequacies in both groups.

physical, emotional, and social domains were most affected by the disease, which was supported by the discussion and feedback from the focus group participants.

Our observation of impaired QOL in CD patients relative to the normal Canadian population and healthy control subjects is consistent with the findings of a number of other studies..$^{9,14,26,32,43}$ In particular, a greater degree of impairment is present in all QOL domains in CD compared with acromegaly, prolactinoma, and NFPA, and the normal population. ${ }^{79}$ A study by Ye and Akagami also demonstrated that QOL in CD patients is impaired relative to that in NFPA patients and the normal population. ${ }^{43}$ Likewise, a significant impairment in both the physical and mental summary scores was observed in CD patients prior to treatment in a study conducted by Lindsay et al. ${ }^{14}$

The impaired QOL observed prior to surgery in our study and overall improvement across all domains of the QOL-CD following surgery are consistent with the findings of Lindsay et al., in which an improvement across all domains of QOL assessed with the SF-36 was observed postoperatively. ${ }^{14} \mathrm{Ye}$ and Akagami also demonstrated that QOL of CD patients improves after surgery. ${ }^{43}$ Despite the improvements, both studies indicated that postoperative QOL continues to remain impaired relative to the normal population. Further studies will need to be conducted in order to assess the progression of QOL outcomes across multiple time points perioperatively.

The effectiveness of the QOL-CD questionnaire to replicate these prior findings and distinguish $\mathrm{CD}$ patients from controls provides further evidence for validity. Despite having good overall concurrent validity with other validated QOL measures, the social well-being scores of the QOL-CD did not correlate well with the SF-36 or the FACT-Br. This poor correlation between the social functioning domain of the SF-36 and the social well-being domain of the QOL-CD may have arisen from differences between the aspect of social health the questionnaire intended to measure and the recall period. The SF-36 social functioning domain sought to measure the respondent's ability to carry out social activities within the context of their physical and emotional impairments (i.e., functioning), whereas the QOL-CD aimed to assess the emotive aspect of social health by assessing the frequency and quality of support from their social relationships (i.e., well-being). Moreover, the recall period of the SF-36 (i.e., 4 weeks) is much longer than the QOL-CD (i.e., 7 days), which may account for lack of correlation due to recall bias. The FACT-Br, which was designed for patients with malignant glioma, likely reflects QOL differently from the QOL-CD as a result of the different nature and pathophysiologies. ${ }^{41}$ Weak correlations between scores on the QOL-CD and the KPS also most likely indicate differences between the construct of each questionnaire. Since QOL is multidimensional and involves more than only the physical aspect, a unidimensional measure of functional status, such as the KPS, is inadequate.

In previous investigations of QOL in CD patients, generic questionnaires, such as the SF-36 and Nottingham Health Profile (NHP), were used extensively. ${ }^{1,2,6,9,12,14,34-36,43}$ In contrast to the generic SF-36 and NHP questionnaires, which are generally limited to assessments of role limitations due to physical and emotional impairments, the disease-specific QOL-CD seeks to assess physical health through items pertaining to $\mathrm{CD}$-specific symptoms generated through ranking of importance by CD patients, which includes items such as presence of headaches, stretch marks, facial hair, and changes in appearance of the face. This allows the QOL-CD to better capture the nuances associated with CD.

In addition, domain-specific measures of QOL, such as the Hospital Anxiety and Depression Scale (HADS) and the Beck Depression Inventory (BDI) were often used in 
previous studies of QOL to assess severity of depressive symptomatology in CD patients. ${ }^{1,12,27,33,35,36}$ Although these questionnaires provide an in-depth measure of depressive symptomatology severity, neither the HADS nor BDI includes measures of change in mood, which has been found to be largely prevalent among CD patients. ${ }^{14,22,30}$ The emotional health domain of the QOL-CD is not restricted to assessments of depression exclusively and was developed to account for the multidimensional nature of psychiatric impairments associated with CD, such as anxiety, mood swings, and irritability.

Webb et al. developed and validated the 12-item CushingQoL questionnaire through a sample of 125 patients with CS. ${ }^{38}$ The instrument developed by Webb et al. did not have distinct domains relevant to multidimensional QOL, such as emotional, cognitive, social, and physical domains. Our finding of impairments in the physical health, emotional health, and social well-being domains emphasizes the importance of having a disease-specific scale that measures multiple domains of QOL considered important by patients with CD. We also showed, in distinction to Webb et al., that these domains change after surgery for CD.

Milian et al. developed the 25-item Tuebingen CD-25 questionnaire through interviews with 10 postoperative CD patients and medical specialists, and it was subsequently validated with a larger cohort. ${ }^{15}$ While this questionnaire encompasses 6 domains (depression, sexual activity, environment, eating behavior, bodily restrictions, and cognition), it focuses primarily on the physical and emotional impact of CD, with particular attention to sexual and eating-related limitations of the disease. Milian et al. found that female patients reported worse QOL than males in subdomains of depressive symptoms and social environment. ${ }^{16}$ Our work shows that patients with CD are concerned with the quality of support and relationship with others. In addition, the QOL-CD possesses a unique medical treatment subdomain, which assesses patient satisfaction with their care.

\section{Limitations}

The methodology undertaken to develop and preliminarily validate the QOL-CD presents several limitations. Since this study only included patients assessed as having "successful" surgical outcomes and did not represent those with refractory cases, a selection bias is present. As a result of this selection, recall bias may arise from the intrinsic differences in the burden and perception of illness between CD patients with successful outcomes and those without. Since patients were invited to participate, the study may be subject to additional selection and nonresponse bias. Participants in the development phase were also asked to recall their QOL retrospectively, which may introduce additional recall bias. Our sample reflected the female preponderance in $\mathrm{CD}$, in which there was a large number of females. As such, the results may not be representative for males, which could potentially make the QOL-CD questionnaire less sensitive in males with CD. Therefore, future investigations of QOL in CD are encouraged to administer the QOL-CD in their cohort and, in particular, should aim to test the QOL-CD in refractory cases, as well as in a larger male CD cohort in order to further demonstrate its generalizability. Furthermore, testing of the CushingQoL questionnaire between CD patients from the US and the Netherlands demonstrated difference in interpretation. ${ }^{42}$ This may be attributed to the fact that perceptions of QOL vary across cultures. ${ }^{13}$ With this in consideration, the QOL-CD should be similarly tested across cultures to determine differences in interpretation.

\section{Conclusions}

We have developed a disease-specific questionnaire to measure the multidimensional nature of QOL in patients with CD. Evidence for the feasibility, reliability, and validity of the QOL-CD has been demonstrated during testing.

\section{References}

1. Alcalar N, Ozkan S, Kadioglu P, Celik O, Cagatay P, Kucukyuruk B, et al: Evaluation of depression, quality of life and body image in patients with Cushing's disease. Pituitary 16:333-340, 2013

2. Carluccio A, Sundaram NK, Chablani S, Amrock LG, Lambert JK, Post KD, et al: Predictors of quality of life in 102 patients with treated Cushing's disease. Clin Endocrinol (Oxf) 82:404-411, 2015

3. Cella DF, Tulsky DS, Gray G, Sarafian B, Linn E, Bonomi A, et al: The Functional Assessment of Cancer Therapy scale: development and validation of the general measure. J Clin Oncol 11:570-579, 1993

4. Cronbach LJ: Designing Evaluations of Educational and Social Programs. Jossey-Bass, 1982

5. Gotch PM: Cushing's syndrome from the patient's perspective. Endocrinol Metab Clin North Am 23:607-617, 1994

6. Hawn MT, Cook D, Deveney C, Sheppard BC: Quality of life after laparoscopic bilateral adrenalectomy for Cushing's disease. Surgery 132:1064-1069, 2002

7. Heald AH, Ghosh S, Bray S, Gibson C, Anderson SG, Buckler $\mathrm{H}$, et al: Long-term negative impact on quality of life in patients with successfully treated Cushing's disease. Clin Endocrinol (Oxf) 61:458-465, 2004

8. Hopman WM, Towheed T, Anastassiades T, Tenenhouse A, Poliquin S, Berger C, et al: Canadian normative data for the SF-36 health survey. CMAJ 163:265-271, 2000

9. Johnson MD, Woodburn CJ, Vance ML: Quality of life in patients with a pituitary adenoma. Pituitary 6:81-87, 2003

10. Karnofsky DA, Abelmann WH, Craver LF, Burchenal JH: The use of the nitrogen mustards in the palliative treatment of carcinoma. With particular reference to bronchogenic carcinoma. Cancer 1:634-656, 1948

11. Karnofsky DA, Burchenal JH: The clinical evaluation of chemotherapeutic agents in cancer, in MacLeod CM (ed): Evaluation of Chemotherapeutic Agents. New York: Columbia University Press, 1949

12. Keskin FE, Özkaya HM, Ortaç M, Salabaş E, Kadıŏlu A, Kadıŏlu P: Sexual function in women with Cushing's syndrome: a controlled study. Turk J Urol 44:287-293, 2018

13. Kuyken W, Orley J, Hudelson P, Sartorius N: Quality of life assessment across cultures. Int J Ment Health 23:5-27, 1994

14. Lindsay JR, Nansel T, Baid S, Gumowski J, Nieman LK: Long-term impaired quality of life in Cushing's syndrome despite initial improvement after surgical remission. J Clin Endocrinol Metab 91:447-453, 2006

15. Milian M, Teufel P, Honegger J, Gallwitz B, Schnauder G, Psaras T: The development of the Tuebingen Cushing's disease quality of life inventory (Tuebingen CD-25). Part I: construction and psychometric properties. Clin Endocrinol (Oxf) 76:851-860, 2012 
16. Milian M, Teufel P, Honegger J, Gallwitz B, Schnauder G, Psaras T: The development of the Tuebingen Cushing's disease quality of life inventory (Tuebingen CD-25). Part II: normative data from 1784 healthy people. Clin Endocrinol (Oxf) 76:861-867, 2012

17. Mor V, Laliberte L, Morris JN, Wiemann M: The Karnofsky Performance Status Scale. An examination of its reliability and validity in a research setting. Cancer 53:2002-2007, 1984

18. Nagesser SK, van Seters AP, Kievit J, Hermans J, Krans HM, van de Velde CJ: Long-term results of total adrenalectomy for Cushing's disease. World J Surg 24:108-113, 2000

19. Newell-Price J, Bertagna X, Grossman AB, Nieman LK: Cushing's syndrome. Lancet 367:1605-1617, 2006

20. Nishisato S: Elements of Dual Scaling: An Introduction to Practical Data Analysis. Hillsdale, NJ: Lawrence Erlbaum Assoc, 1994

21. Nunnally JC: Psychometric Theory. New York: McGrawHill, 1978

22. Pasternak-Pietrzak K, Moszczyńska E, Roszkowski M, Kot $\mathrm{K}$, Marczak E, Grajkowska W, et al: Long-term outcome in patients after treatment for Cushing's disease in childhood. PLoS One 14:e0226033, 2019

23. Pecori Giraldi F, Moro M, Cavagnini F: Gender-related differences in the presentation and course of Cushing's disease. J Clin Endocrinol Metab 88:1554-1558, 2003

24. Péus D, Newcomb N, Hofer S: Appraisal of the Karnofsky Performance Status and proposal of a simple algorithmic system for its evaluation. BMC Med Inform Decis Mak 13:72, 2013

25. Pivonello R, De Martino MC, De Leo M, Simeoli C, Colao A: Cushing's disease: the burden of illness. Endocrine 56:10-18, 2017

26. Psaras T, Milian M, Hattermann V, Will BE, Tatagiba M, Honegger J: Predictive factors for neurocognitive function and Quality of Life after surgical treatment for Cushing's disease and acromegaly. J Endocrinol Invest 34:e168-e177, 2011

27. Santos A, Resmini E, Crespo I, Pires P, Vives-Gilabert Y, Granell E, et al: Small cerebellar cortex volume in patients with active Cushing's syndrome. Eur J Endocrinol 171:461469, 2014

28. Santos A, Resmini E, Martínez-Momblán MA, Crespo I, Valassi E, Roset M, et al: Psychometric performance of the CushingQoL questionnaire in conditions of real clinical practice. Eur J Endocrinol 167:337-342, 2012

29. Sonino N, Bonnini S, Fallo F, Boscaro M, Fava GA: Personality characteristics and quality of life in patients treated for Cushing's syndrome. Clin Endocrinol (Oxf) 64:314-318, 2006

30. Tang A, O'Sullivan AJ, Diamond T, Gerard A, Campbell P: Psychiatric symptoms as a clinical presentation of Cushing's syndrome. Ann Gen Psychiatry 12:23, 2013

31. Thavarajah N, Bedard G, Zhang L, Cella D, Beaumont JL, Tsao M, et al: Psychometric validation of the Functional Assessment of Cancer Therapy-Brain (FACT-Br) for assessing quality of life in patients with brain metastases. Support Care Cancer 22:1017-1028, 2014

32. Tiemensma J, Kaptein AA, Pereira AM, Smit JWA, Romijn JA, Biermasz NR: Negative illness perceptions are associated with impaired quality of life in patients after long-term remission of Cushing's syndrome. Eur J Endocrinol 165:527535,2011

33. Valassi E, Crespo I, Keevil BG, Aulinas A, Urgell E, Santos A, et al: Affective alterations in patients with Cushing's syndrome in remission are associated with decreased BDNF and cortisone levels. Eur J Endocrinol 176:221-231, 2017

34. van Aken MO, Pereira AM, Biermasz NR, van Thiel SW, Hoftijzer HC, Smit JWA, et al: Quality of life in patients after long-term biochemical cure of Cushing's disease. J Clin Endocrinol Metab 90:3279-3286, 2005

35. van der Klaauw AA, Kars M, Biermasz NR, Roelfsema F, Dekkers OM, Corssmit EP, et al: Disease-specific impairments in quality of life during long-term follow-up of patients with different pituitary adenomas. Clin Endocrinol (Oxf) 69:775-784, 2008

36. Wagenmakers MA, Netea-Maier RT, Prins JB, Dekkers T, den Heijer M, Hermus AR: Impaired quality of life in patients in long-term remission of Cushing's syndrome of both adrenal and pituitary origin: a remaining effect of longstanding hypercortisolism? Eur J Endocrinol 167:687-695, 2012

37. Ware JE Jr, Sherbourne CD: The MOS 36-item short-form health survey (SF-36). I. Conceptual framework and item selection. Med Care 30:473-483, 1992

38. Webb SM, Badia X, Barahona MJ, Colao A, Strasburger CJ, Tabarin A, et al: Evaluation of health-related quality of life in patients with Cushing's syndrome with a new questionnaire. Eur J Endocrinol 158:623-630, 2008

39. Webb SM, Crespo I, Santos A, Resmini E, Aulinas A, Valassi E: Management of endocrine disease: quality of life tools for the management of pituitary disease. Eur J Endocrinol 177:R13-R26, 2017

40. Webb SM, Santos A, Resmini E, Martínez-Momblán M-A, Martel L, Valassi E: Quality of life in Cushing's disease: a long term issue? Ann Endocrinol (Paris) 79:132-137, 2018

41. Weitzner MA, Meyers CA, Gelke CK, Byrne KS, Cella DF, Levin VA: The Functional Assessment of Cancer Therapy (FACT) scale. Development of a brain subscale and revalidation of the general version (FACT-G) in patients with primary brain tumors. Cancer 75:1151-1161, 1995

42. Winter SD, Depaoli S, Tiemensma J: Assessing differences in how the CushingQoL is interpreted across countries: comparing patients from the U.S. and the Netherlands. Front Endocrinol (Lausanne) 9:368, 2018

43. Ye VC, Akagami R: Perioperative quality of life in Cushing's disease. Can J Neurol Sci 44:69-77, 2017

\section{Disclosures}

The authors report no conflict of interest concerning the materials or methods used in this study or the findings specified in this paper.

\section{Author Contributions}

Conception and design: Cusimano. Acquisition of data: all authors. Analysis and interpretation of data: all authors. Drafting the article: all authors. Critically revising the article: all authors. Reviewed submitted version of manuscript: all authors. Approved the final version of the manuscript on behalf of all authors: Cusimano. Statistical analysis: Cusimano, Huang, Marchie. Administrative/technical/material support: all authors. Study supervision: Cusimano.

\section{Supplemental Information \\ Online-Only Content}

Supplemental material is available online.

Supplement 1. https://thejns.org/doi/suppl/10.3171/2020.3. FOCUS2044.

\section{Correspondence}

Michael D. Cusimano: St. Michael's Hospital, University of Toronto, ON, Canada. injuryprevention@smh.ca. 